\title{
Fiber-reinforced composites in fixed prosthodontics-Quo vadis?
}

Vallittu, Pekka K ; Shinya, Akikazu ; Baraba, Anja ; Kerr, Ian ; Keulemans, Filip ; Kreulen, Cees ; Lassila, Lippo ; Malmstrom, Hans ; Novotny, Rudolf ; Peumans, Marleen ; Van Rensburg, Jansie ; Wolff, Diana ; Òzcan, Mutlu

DOI: https://doi.org/10.1016/j.dental.2017.05.001

Posted at the Zurich Open Repository and Archive, University of Zurich ZORA URL: https://doi.org/10.5167/uzh-146151

Journal Article Accepted Version

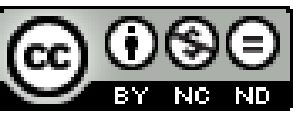

The following work is licensed under a Creative Commons: Attribution-NonCommercial-NoDerivatives 4.0 International (CC BY-NC-ND 4.0) License.

Originally published at:

Vallittu, Pekka K; Shinya, Akikazu; Baraba, Anja; Kerr, Ian; Keulemans, Filip; Kreulen, Cees; Lassila, Lippo; Malmstrom, Hans; Novotny, Rudolf; Peumans, Marleen; Van Rensburg, Jansie; Wolff, Diana; Özcan, Mutlu (2017). Fiber-reinforced composites in fixed prosthodontics-Quo vadis? Dental Materials, 33(8):877-879.

DOI: https://doi.org/10.1016/j.dental.2017.05.001 
Fiber-Reinforced Composites in Fixed Prosthodontics - Quo Vadis?

\author{
Pekka K. Vallittu, ${ }^{\mathrm{a}, \mathrm{b}}$ Akikazu Shinya, ${ }^{\mathrm{a}, \mathrm{c}}$ Anja Baraba, ${ }^{\mathrm{d}}$ Ian Kerr, ${ }^{\mathrm{e}}$ Filip \\ Keulemans, ${ }^{\text {a }}$ Cees Kreulen, ${ }^{9}$ Lippo Lassila, ${ }^{a}$ H. Malmstrom, ${ }^{\text {h }}$ R. Novotny \\ R, ${ }^{i}$ Marleen Peumans, ${ }^{j}$ J. Van Rensburg, ${ }^{,}$Diana Wolff,' Mutlu Özcan ${ }^{m}$
}

${ }^{a}$ Department of Biomaterials Science and Turku Clinical Biomaterials

Centre-TCBC, Institute of Dentistry, University of Turku, Turku, Finland

${ }^{b}$ City of Turku, Welfare Division, Finland

cDepartment of Crown and Bridge, School of Life Dentistry at Tokyo, The

Nippon Dental University, Tokyo, Japan

${ }^{d}$ Department of Endodontics and Restorative Dentistry, School of Dental

Medicine, University of Zagreb, Zagreb, Croatia

${ }^{e} X X X$

${ }^{g} X X X$

h Department of General Dentistry, University of Rochester, Eastman Institute

for Oral Health, Rochester New York,

iPrivate Dentist, Kosice, Slovakia

\begin{abstract}
j Associate Professor;
KU Leuven - BIOMAT, Department of Oral Health Sciences, KU Leuven \& Dentistry, University Hospitals Leuven, Kapucijnenvoer

7, B-3000 - Leuven, Belgium

${ }^{k} X X X$

'University of Heidelberg, Department of Conservative Dentistry, Heidelberg, Germany

mUniversity of Zurich, Dental Materials Unit, Center for Dental and Oral Medicine, Clinic for Fixed and Removable Prosthodontics and Dental Materials Science, Zurich, Switzerland
\end{abstract}


*Corresponding author:

Prof. Pekka Vallittu

Institute of Dentistry

University of Turku

Lemminkäisenkatu 2

FI-20520 Turku, FINLAND

Email: pekka.vallittu@utu.fi

Fiber-reinforced composite (FRC) materials introduced to dentistry more than five decades ago [1]. Following extensive research and, it took more than twenty-five years until FRCs were first indicated as a reconstruction material for fixed dental prostheses (FPDs) [2-4]. Early FRC FPDs were used in the design of full coverage crown retainers but the rationale for using indirect crown-retained FRC FPDs were questioned it became evident that the longevity of the FDPs was not as favourable as porcelain-fused-to-metal FDPs [5]. Glass FRCs fulfilled this requirement and active research on direct surface- or intra-coronally-retained FRC FDPs commenced [6-8]. twenty-five years the beginning of effective FRC FDP research, some conclusions could be drawn on the rationale for indicating FRC FPDs and some statements could be made on possible risk factors that may affect the longevity of the treatment outcome with such reconstructions. In this regard, a consensus meeting on the current status FRC FDPs was held in Leuven, BelgiumSeptember 23 ${ }^{\text {rd }}, 2016$.

Longevity of the FRC FDPs has been evaluated in limited number clinical studies various FDP designs, material combinations and cementing systems employed. The majority of the available studies were often criticized due to heterogeneous nature of FDPs evaluated systematic review,, only moderate success for indirect FRC FDPs [9]. However, once the FRCs started to be 
used in conjunction with the direct technique, more encouraging clinical results have been reported [10-12], short or mid-term follow-up results are available. Depending on the expectations longevity of an FDP, , from the present clinical experience with direct FRC FDPs, that such reconstructions could be considered as definite prosthodontics solutions with survival time of five to six years. The use of FRC materials expanded from direct, semi-direct or indirect FRC FDPs to other indications periodontology, orthodontics, conservative dentistry and fixed prosthodontics.

When benefits of FRC FDPs were discussed, the dentists proposed principal arguments:

1.FRC materials allows for following the Dynamic Treatment Concept (life-long dental treatment starting with the least invasive treatment preserving the maximum amount of tooth substance that would save the dental hard tissues for possible prospective treatments even years after the first intervention), 2.minimal invasiveness,

3.profitable and affordable treatment options and

4.high patient satisfaction.

From the patient perspective, the most significant reasons for selecting FRC FDPs seems to be:

1.the possibility of receiving the FDP in a single-visit,

2.being less expensive and painless treatment and

3.the possibility of avoiding removable devices. 
Apparently, many reasons of these kinds are relevant for specific groups of patients but some of them are valid arguments regardless of the patient background or the country where treatment is provided. However, it was emphasized that decision the type of dental treatment and material is largely affected by the regulations of the national health insurance systems, or subjective demands of the patients.

Some risk factors could be identified that could decrease the longevity of FRC FDPs material type, FDP design, oral environment and hygiene. The decreased treatment expenses could essentially increase the indication of FRC FDPs patients with less attention to and awareness their oral hygiene. Consequently, such factors could affect the treatment outcome of any dental treatment with increased risk for caries and periodontal diseases. In addition, occlusion and especially limited vertical space seems to represent major risk factor for damage in FRC FDPs. Essentially, without adequate inter-occlusal space, optimum design and dimensions of FRC FDPs could not be accomplished. Minimal requirements for the inter-occlusal space are $4.0 \mathrm{~mm}$ for pontic, $2.5 \mathrm{~mm}$ for the connector area (vertically in the posterior and palato/linguo-buccally in the anterior region) and $2.0 \mathrm{~mm}$ for the occlusal surface of the abutment. Furthermore, increased mobility of abutment teeth appears to increase the risk for debonding of intracoronal retainers and periodontal splints. increased mobility of abutments is, additional surface bonding wings or crown retainers with the cantilever FDP design be considered. 
Increased expectations for fixed reconstructions have increased the demand for developing treatment alternatives for partially edentulous patients. Significant improvements in adhesive techniques and mechanical properties of resin composites using FRC materials have increased the indication of adhesive FRC FDPs. Nevertheless, understanding and managing the risk factors dictate the successful use of direct or indirect FRC FDP treatment modalities. Based on the present knowledge and experience, with sufficient inter-occlusal space, correct design and precise application of adhesive techniques, FRC FDPs could provide fixed prosthodontic solutions, with expected survival time of at least five to six years high patient satisfaction.

\section{References}

[1] Smith DC. Recent developments and prospects in dental polymers. J Priosthet Dent 1962;12:1066-78.

[2] Ladizesky NH, Chow TW. The effect of highly drawn poilyethylene fibers on the mechanical properties of denture base resins. Clin Mater 1990;6:209-25.

[3] Vallittu PK. Comparison of two different silane compounds used for improving adhesion between fibers and acrylic denture base material. J Oral Rehabil 1993;20:533-9.

[4] Goldberg AJ, Burstone CJ. The use of continuous fiber reinforcement in dentistry. Dent Mater 1992;8:197-202.

[5] Körber HK, Körber S. Experimentelle Untersuchungen zur Passgenauigkeit von GFK-Bruckengerusten “Vectris”. Quintessence Zahnyech 1998;24:43-53. 
[6] Shannon A. Fiber-reinforced composite bridger. Inlayto-inlay technique. Dent Today 1997;16:50-3.

[7] Arteaga S, Meiers JC. Single-tooth replacement with chairside prefabricated fiber-reinforced resin composite bridge: a case study. Gen Dent 2004;52:517-9.

[8] Vallittu PK, Sevelius C. Resin-bonded, glass fiber-reinforced composite fixed partial dentures: a clinical study. J Prosthet Dent 2000;84:413-8.

[9] van Heumen CC, Kreulen CM, Creugers NH. Clinical studies of fiber-reinforced resin-bonded fixed partial dentures: a systematic review. Eur J Oral Sci 2009;117:1-6.

[10] Kumbuloglu O, Özcan M. Clinical survival of indirect, anterior 3-unit surface-retained fibre-reinforced composite fixed dental prosthesis. Up to 7.5-years follow-up. J Dent 2015;43:656-63.

[11] Malmstrom H, Dellanzo-Savu A, Xiao J, Feng C, Jabeen A, Romero M, Huang J, Ren Y, Yunker MA. Success, clinical performance and patient satisfaction of direct fibre-reinforced composite fixed partial dentures - a two-year clinical study. J Oral Rehabil 2015;42:906-13.

J Prosthet Dent. 2014 Aug;112(2):143-9.

Fiber-reinforced composite fixed dental prostheses in the anterior area: a 4.5-year follow-up. Frese C, Schiller P, Staehle HJ, Wolff D. 
